\title{
Application Possibilities of Low-temperature Repairs by Welding for Creep-resistance Material GX12CrMoVNb9-1
}

Jaromir Moravec, Iva Novakova, Jiri Sobotka

Technical University of Liberec. Studentská 2, 46117 Liberec 1. Czech Republic. E-mail: iva.novakova@tul.cz

Paper is focused on the area of the energy devices working under the higher temperatures and pressures. It deals with repair of new and operational-loaded components of steam and gas turbines (valve and turbine chamber, transmitters, vane carriers, flap-lockable valve bodies and so on). Generally, there occur different types of defects at production and operating of these parts. Many defects are caused by casting (shrinkage cavities, pores, cracks) and fatigue defects. Eventually, there can occur also production defects. Moreover, most of the defects in the mentioned parts generally take effect not until during the subsequent technological operations. However, in such phase of production, only welding technology can be used to repair the given part. That's why as a goal of this paper there was to find such repair welding procedures which ensure the serviceability of mentioned devices in the standard mode indeed at application of the lower tempering temperatures in comparison to the commonly requirements for material GX12CrMoVNb9-1. Lower tempering temperatures have a strong influence on elimination the deformation as well as on the surface oxidation of the machined components.

Keywords: Welding, Heat Treatment, GX12CrMoVNb9-1, Repairing, Strengthening

\section{Introduction}

At production and running of casted turbine components from the creep resistance materials can take effect different types of defects caused either by used production technologies or due to the subsequent operational loading. However, combinations of highlyalloyed material, shape complexity, high weight and dimensions of casted part don't allow to fully eliminate production defects $[1,2,3,4]$. Visually detected defects are repaired directly in the foundries with subsequent specified heat treatment of the whole part in furnace (for martensitic steels tempering at temperatures 710 up to $740^{\circ} \mathrm{C}$ ). Then during inspection is every part checked visually and also by ultrasonic and eddy current NDT [5, $6,7]$. Nevertheless, it is not possible to detect all defects. Some defects are generally detected at subsequent technological operations, mainly during/after machining when the given part already has the final assembly dimensions. Moreover, during these processes can occur (or are created) another defects as fractures in the zones of local stress waves. Beside the mentioned types of defects can be at energy devices detected also defects caused by operational conditions (parameters and purity of steam, blackouts, starting rates and so on), eventually by infringement of the specified operational parameters by operator (e.g. unauthorized use or manipulation). [7, $8,9]$

To repair mentioned defects there are generally used covered electrodes (111 acc. to ISO 4063). It is necessary to perform welding with pre-heating and the whole part (eventually the area for repairing) is heat treated after welding. If it is possible with respect to part dimensions, heat treatment can be performed in the furnace. In the case of abnormal part is pre-heating and subsequent heat treatment ensured by the electric heating elements (muffs). However, at this type of repair can't be applied standard procedures with high pre-heating temperatures and subsequent heat treatment. Repairs have to be proposed in such manner to eliminate deformation of machined surfaces and accumulation of plastic stress, because of keeping the planned operational service life of repairing parts. Moreover, there have to be elimate occurrence of undesirable structural changes. During the repairing of components, which already have been operated for a long-time, it is necessary to take into account also thermal degradation of basic material.

\section{Experimental part}

Within the experiment there was used the martensitic steel GX12CrMoVNb9-1 (P91). It is the steel alloyed by chromium $(\mathrm{Cr})$, vanadium $(\mathrm{V})$ and niobium $(\mathrm{Nb})$ with the controlled content of boron (B) and nitrogen (N). Among the most important strengthening mechanisms, which take strong effect during high-temperature explosion of such type heat-resisting and modified steels, there are precipitation strengthening and solid solution substitutional strengthening.

Microstructural stability of this steel is positively influenced by low coarse-rate $\mathrm{M}_{23} \mathrm{C}_{6}$ particles type that is closely related with the solution of $\mathrm{B}$ atoms in the given phase. It is due to fact that during creep loading, there is growing and subsequent coarsing of these particles, whereas coarse-rate increases with the increasing $\mathrm{Cr}$ content in steels. Another creep resistance increase is done by nitrogen alloying and also due to vanadium nitride precipitation within the grain.

Thus solid solution strengthening is subsequently achieved by substitution, whereas the main influence has the increasing molybdenum content in the solid solution. It can be also substitutional strengthened by the same mechanism as using tungsten (W) - as it is already used at steel P92. Moreover, there was proved that there is no reason to increase the molybdenum equivalent content in steel over the solubility limit. Higher Mo and W content in steels results in secondary phases precipitation which are rich in $\mathrm{Mo}$ or $\mathrm{W}$ - e.g. $\mathrm{M}_{6} \mathrm{X}$ and $(\mathrm{Fe}, \mathrm{Cr})_{2}(\mathrm{Mo}, \mathrm{W})$. So finally there is lowering of solid solution strengthening 


\section{$[10,11,12,13]$.}

Steels P91 were developed to be used in USC powerstations within the temperature range $600-620^{\circ} \mathrm{C}$ and pressures about $26 \mathrm{MPa}$. They are wide-spread mainly at steam systems working in combined-cycle. As a reason for that there is their high temperature stability and resistance against thermal fatigue during heating and cooling.

In Fig. 1 is shown the structure of delivered material GX12CrMoVNb9-1. It is tempered martensitic material with the initial hardness $214 \mathrm{HV}$ for loading that corresponds to method HV10 acc. to ČSN EN ISO 65071. In Tab. 1 is shown the chemical composition of P91 steel determined by spectrometer Q4 Tasman and in Tab. 2 are summarized values of mechanical properties measured at samples from this tested material.

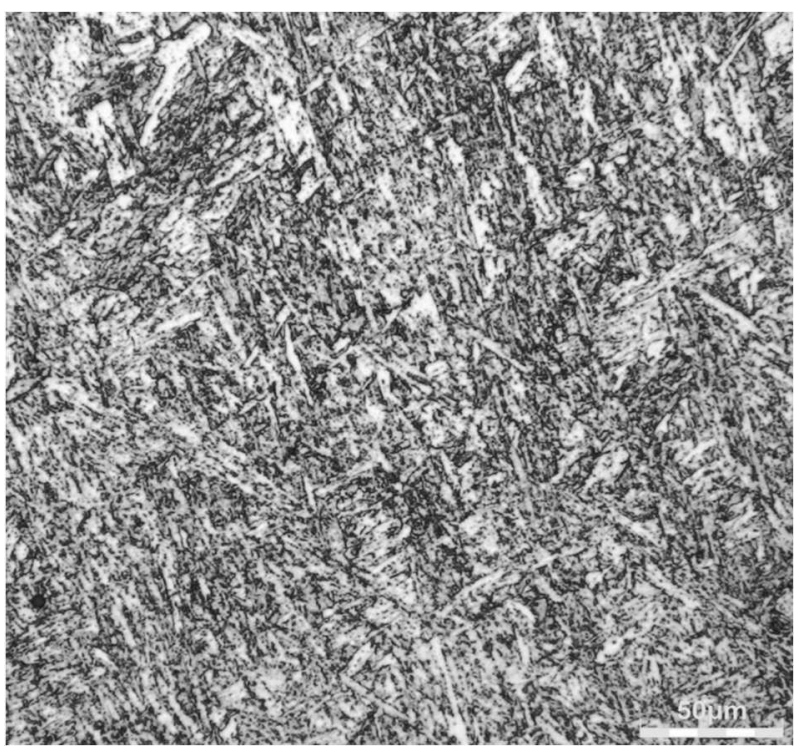

Fig. 1 Structure of tested steel GX12CrMoVNb9-1

Tab. 1 Chemical composition of GX12CrMoVNb9-1 determined by spectrometer Q4 Tasman

Chemical composition of GX12CrMoVNb9-1 [wt.\%]

\begin{tabular}{|c|c|c|c|c|c|c|c|c|}
\hline $\mathbf{C}$ & $\mathbf{S i}$ & $\mathbf{M n}$ & $\mathbf{C r}$ & $\mathbf{M o}$ & $\mathbf{N i}$ & $\mathbf{V}$ & $\mathbf{N}$ & $\mathbf{N b}$ \\
\hline 0.13 & 0.39 & 0.43 & 7.98 & 0.94 & 0.29 & 0.23 & 0.07 & 0.07 \\
\hline
\end{tabular}

Tab. 2 Measured mechanical properties of delivered steel 1991

\begin{tabular}{|c|c|c|c|c|c|}
\hline $\begin{array}{c}\text { Yield strength } \\
\mathbf{R}_{\mathrm{p} 0,2} \text { at } 20^{\circ} \mathrm{C} \\
{[\mathrm{MPa}]}\end{array}$ & $\begin{array}{c}\text { Yield strength } \\
\mathrm{R}_{\mathrm{p} 0,2} \text { at } \mathbf{4 0 0}^{\circ} \mathrm{C} \\
{[\mathrm{MPa}]}\end{array}$ & $\begin{array}{c}\text { Ultimate } \\
\text { strength } R_{m} \text { at } \\
20^{\circ} \mathrm{C} \\
{[\mathrm{MPa}]}\end{array}$ & $\begin{array}{c}\text { Ultimate } \\
\text { strength } \mathrm{R}_{\mathrm{m}} \text { at } \\
400^{\circ} \mathrm{C} \\
{[\mathrm{MPa}]}\end{array}$ & $\begin{array}{c}\text { Total ductility } \\
\text { A5 at } 20^{\circ} \mathrm{C} \\
{[\%]}\end{array}$ & $\begin{array}{c}\text { Impact energy } \\
\mathrm{KV} 2 \text { at } 20^{\circ} \mathrm{C} \\
{[\mathbf{J}]}\end{array}$ \\
\hline 514 & 439 & 668 & 534 & 19.4 & 38 \\
\hline
\end{tabular}

Before the classification of welding procedures and creation WPS, there was needed to create preliminary welding repairs procedure pWPS, which needs to be verified experimentally - both in light of welding and in light of subsequent heat treatments of welds. Experimental verification is commonly performed at samples which correspond to repairs on the real part. In this case there was multiple joint performed into the groove milled into the blank of desk shape and having dimensions $400 \times 150 \times 50 \mathrm{~mm}$. Groove was created along the whole length of desk with depth $20 \mathrm{~mm}$, width of the lower groove edge $15 \mathrm{~mm}$, transient radii $\mathrm{R} 5$ and width of the upper grove edge $25 \mathrm{~mm}$. This groove is schematically shown in Fig. 2.

Groove (see Fig. 2) was totally filled by 21 runs in seven layers over each other, whereas each of them contained 3 runs side-by-side. It was welded by method 111 acc. to ISO 4063 and by electrodes BÖHLER FOX C $9 \mathrm{MV}$. Root run (first layer) was welded by the electrodes with diameter $2,4 \mathrm{~mm}$; layers of filling runs by the electrodes with diameter 3,2 and 4,0 $\mathrm{mm}$ and finally layer of capping runs by the electrodes with diameter 5,0 mm. Repairing by welding was done by pre-heating of part at temperature $\min .400^{\circ} \mathrm{C}$ and interpass temperature $500^{\circ} \mathrm{C}$. So during the whole time of repairing was temperature held slightly over the temperature Ms. Preheating was performed by means of resistance heating elements (muffs) connected to the device Weldotherm 1, whereas the whole welding sample was wrapped in insulating cotton Sibral. After welding was sample cooled-down (under control) at temperature $120^{\circ} \mathrm{C}$ so there can take effect the full martensitic transformation in the repair area. It was followed by heat treatment after holding time 2 Hrs.

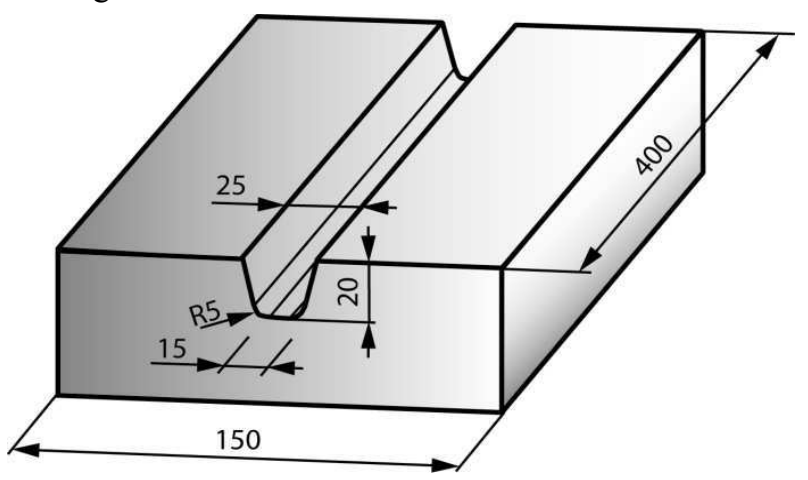

Fig. 2 Geometry of groove used for the multiple weld

In the case of standard welding procedures for steel GX12CrMoVNb9-1 is there after welding heat treatment that consists of heating at temperature $730^{\circ} \mathrm{C}$ with holding on that temperature (holding time) for 4 up to 8 Hrs. However, in the case of repairing there can't be used, due to the reasons mentioned in chapter 1 , so high values of heat treatment. That is why there was in the $1^{\text {st }}$ phase proposed to apply tempering temperature $550^{\circ} \mathrm{C}$ for repairing. To be specific, there was heating by heating rate $100^{\circ} \mathrm{C} / \mathrm{Hr}$ at the tempering temperature $550^{\circ} \mathrm{C}$, 
holding time 6 Hrs and subsequent cooling by cooling rate $50^{\circ} \mathrm{C} / \mathrm{Hr}$ at temperature $300^{\circ} \mathrm{C}$. Sample cooled down spontaneously in wrap after that.

Properties of such welded and also heat treated part were firstly evaluated by measurement the hardness acc. to Vickers HV10 on device Qness Q30A. From the heat treated part were taken samples for subsequent metallographic evaluation and hardness measurement. Samples were processed by the common metallographic procedure. The etchant Villela Bain was used to highlight the structure. Hardness was measured from the parent material over HAZ into the weld metal. Totally there were applied 303 incisions, which were distributed in 7 longitudinal and 3 transverse rows in such manner to evaluate hardness in every of 7 welding layers. Incisions were acc. to standard ČSN EN ISO 9015-1 for loading HV10 performed with axial distance $1 \mathrm{~mm}$.

Measured hardness values are shown in Fig. 3. In the case of weld joint, hardness value in the weld metal and in HAZ should not get over magnitude $350 \mathrm{HV}$. For better orientation are in Fig. 3 hardness values lower than 350 $\mathrm{HV}$ shown in yellow, hardness values within the range 350 up to $379 \mathrm{HV}$ are shown in blue and finally hardness values over $380 \mathrm{HV} 10$ are shown in red.

From the results is evident that tempering at temperature $550^{\circ} \mathrm{C}$ for $6 \mathrm{Hrs}$ is completely insufficient. Hardnesses of weld metal and also HAZ significantly got over the maximal allowable $350 \mathrm{HV}$. Because of that, there was decided to extend the holding time at tempering temperature $550^{\circ} \mathrm{C}$ on $30 \mathrm{Hrs}$. Result of such heat treatment is shown in Fig. 4. From the measured values arise that even in this case isn't proposed heat treatment in light of hardness in the weld metal sufficient. There is a certain decrease of hardness values, but on the other hand is this decrease still insufficient. Another extend of tempering time seemed to be ineffective and that is why there was decided to increase tempering temperature up to $580^{\circ} \mathrm{C}$. Holding time (holding at tempering temperature) was the same as in the previous case - thus 30 Hrs (see Fig. 5). In this case of such heat treated sample took effect the higher decrease of hardness mainly in the weld metal. Nevertheless, measured hardness values in the weld metal varied within the range 350 up to $370 \mathrm{HV}$. In HAZ were these values even smaller - hardness values over $350 \mathrm{HV}$ were measured only very close to the melting boundary. However, even this result is not very suitable for the consider repairing. So finally there was made another decision to again increase tempering temperature on magnitude $595^{\circ} \mathrm{C}$. In this case (see Fig. 6), the whole heat affected zone revealed hardness values lower than $350 \mathrm{HV}$. In addition - these values didn't get over $342 \mathrm{HV}$. Also in the weld metal was determined the strong decrease of hardness and the whole area had hardness lower than $350 \mathrm{HV}$. As an exception, there was only a small area in the middle of weld metal that corresponds to boundary between runs 11 and 14.

Measured results would have been verified by the impact bending test in accordance with ČSN ISO 148-1. Placing of testing samples in the weld joint and notch orientation was performed acc. to ČSN EN ISO 9016. Samples were prepared for testing both in HAZ (VHT $0 / 3$ ) and in the weld metal (VWT 0/3 and VWT 5/3). Test was performed on the Charpy impact tester LabTest CHK 450J - always with 3 samples. Measured values of impact energy KV2 and impact toughness KCV2 are shown in Tab. 3.

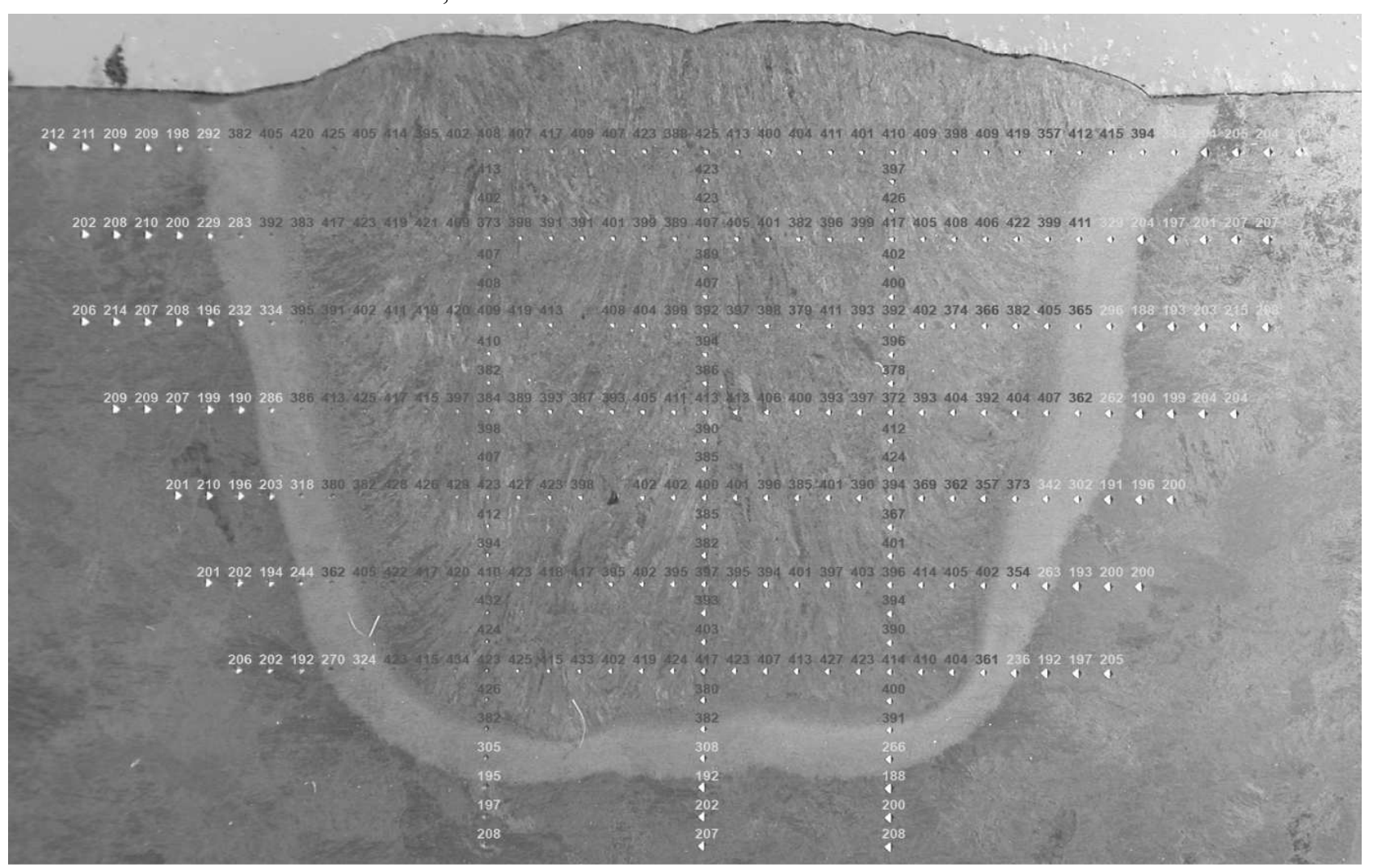

Fig. 3 Hardness values for multiple weld after welding and heat treatment at $550^{\circ} \mathrm{C}$ with holding time $6 \mathrm{Hrs}$ 


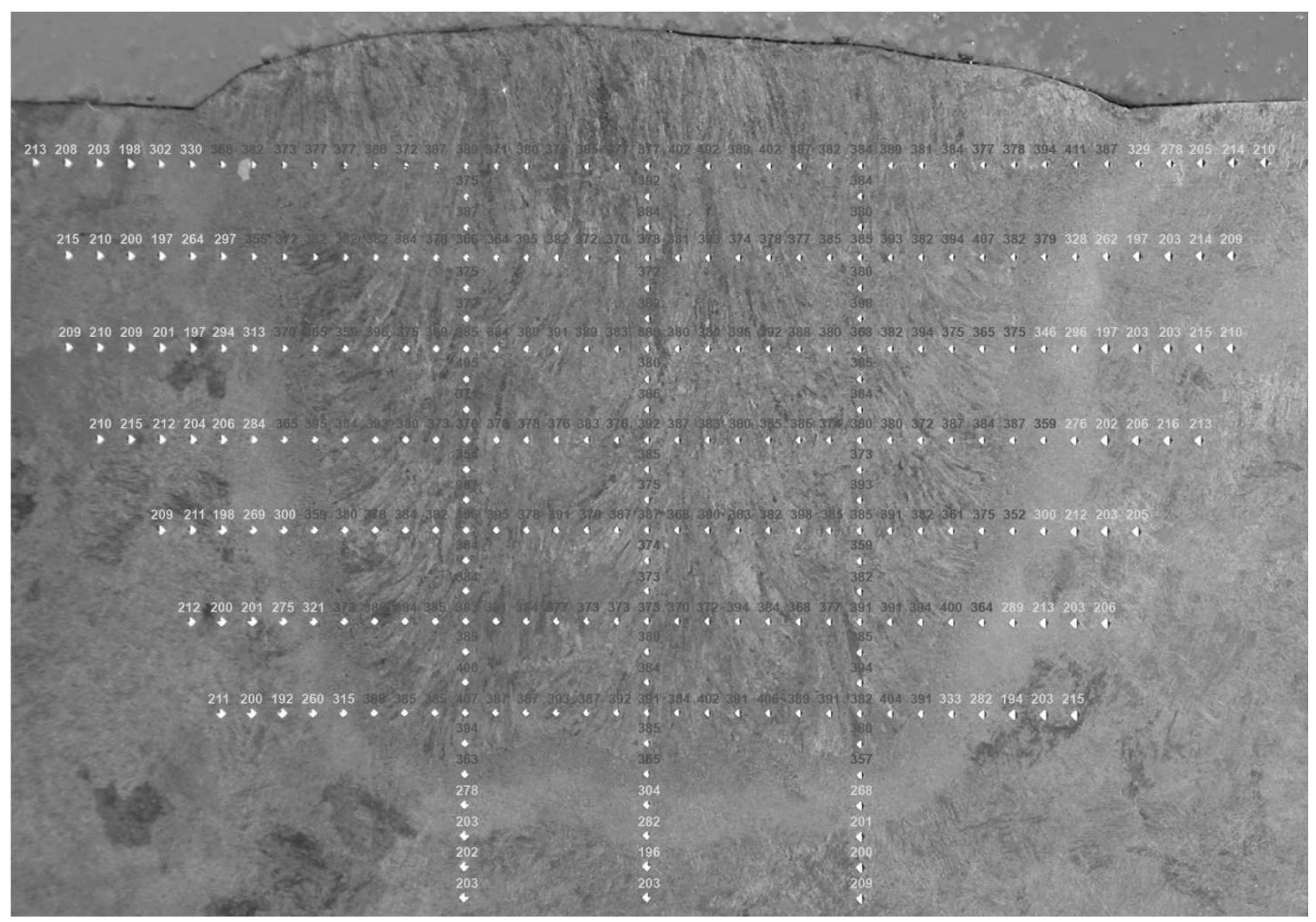

Fig. 4 Hardness values for multiple weld after welding and heat treatment at $550^{\circ} \mathrm{C}$ with holding time $30 \mathrm{Hrs}$

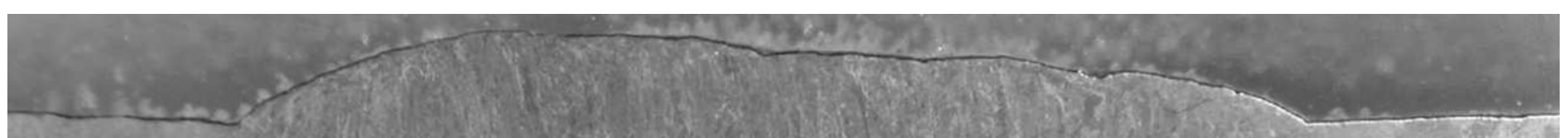

206198200242296327346336340339341355343343345344335343353339338340339336348341352345348349345359345358351323279211209921725

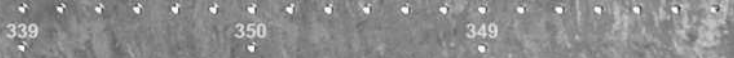

$\begin{array}{ccc}339 & 350 & 349 \\ 342 & 342 & 336\end{array}$

199200243260314346342341346342345340346341336348344343339352345348342343349343357349353362338337287260193199206219212

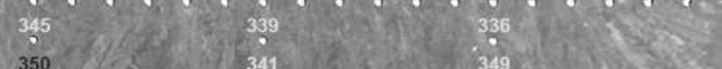

209200196201275312349346339347342348350337349345339335350349339349349343350351351343360334355304259197201207209216218

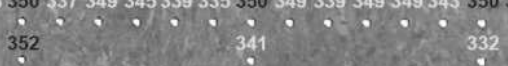

$348+347 \quad-349$

203201189255296341348336335347335355354353350346345346346346340340347351343337347353354339289242203201210216215

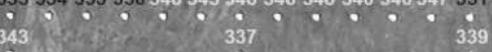

199199259302337343340345335344344337352331346341340338347336346350341341343346353291267204204207209

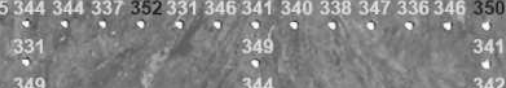

192199270313335342343335346343345332337339340342345338342338343343345352353311258197,199196208

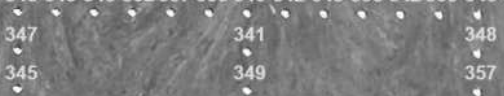

$197190276317344350352346 \times x \quad 358351345352.354358351341354343347346348346295247191196200206$

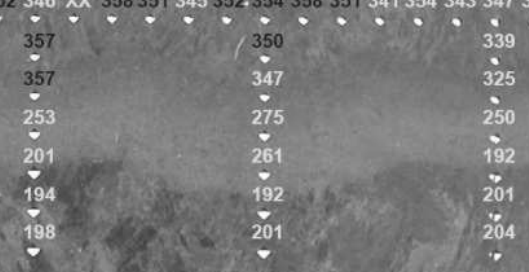

Fig. 5 Hardness values for multiple weld after welding and heat treatment at $580^{\circ} \mathrm{C}$ with holding time $30 \mathrm{Hrs}$ 


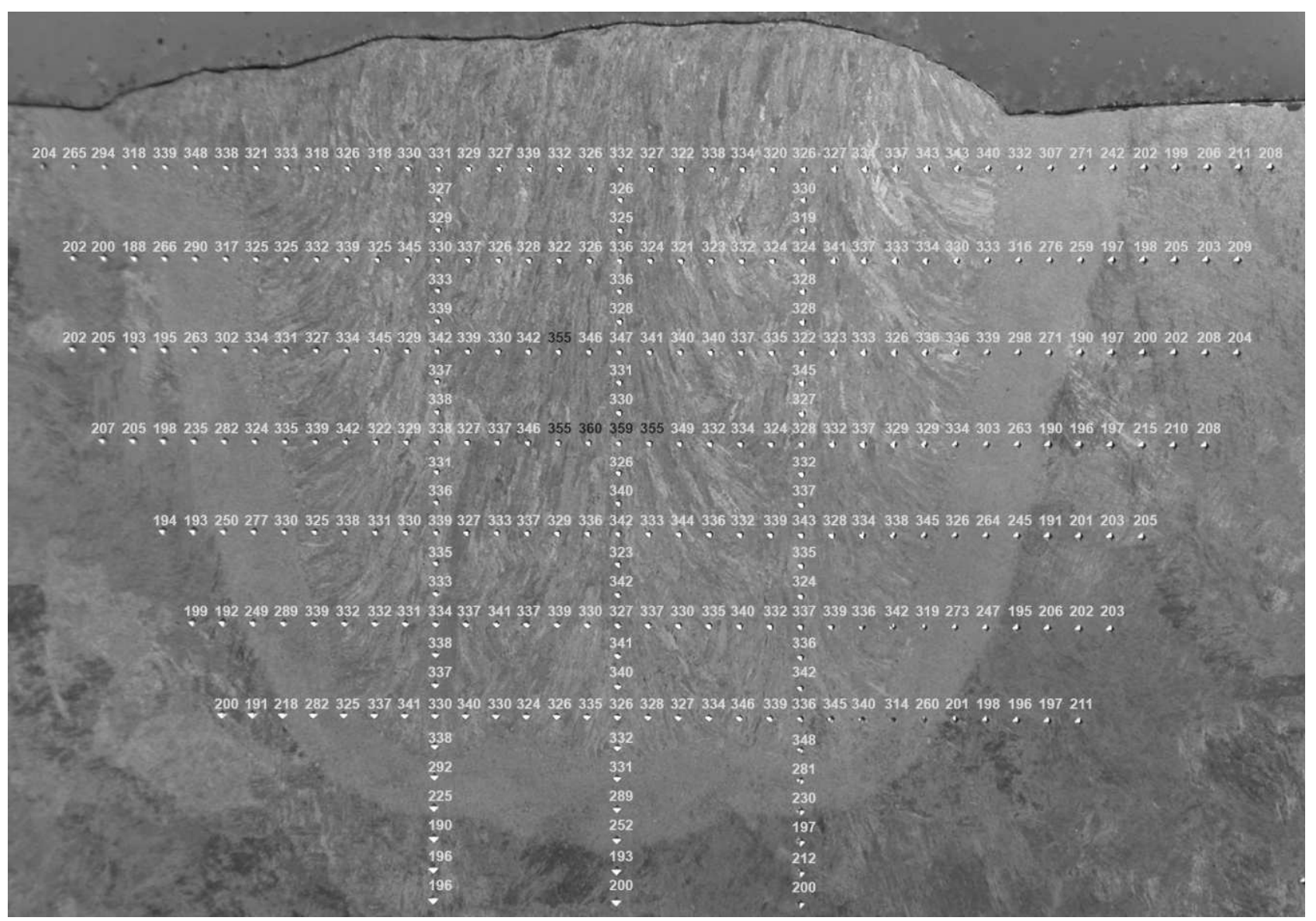

Fig. 6 Hardness values for multiple weld after welding and heat treatment at $595^{\circ} \mathrm{C}$ with holding time $30 \mathrm{Hrs}$

Tab.3 Measured values of $\mathrm{KV}_{2}$ and $\mathrm{KCV}_{2}$

\begin{tabular}{|c|c|c|c|c|c|c|}
\hline \multirow[b]{2}{*}{ No. of sample } & \multicolumn{2}{|c|}{ VHT 0/3 } & \multicolumn{2}{|c|}{ VWT 0/3 } & \multicolumn{2}{|c|}{ VWT 5/3 } \\
\hline & KV2 [J] & KCV2 $\left[J^{-c^{-2}}\right]$ & KV2 [J] & KCV2 $\left[J^{-c^{-2}}\right]$ & KV2 [J] & $\begin{array}{c}\mathrm{KCV} 2\left[\mathrm{~J}_{2}\right. \\
\mathrm{J}^{-\mathrm{cm}^{-}}\end{array}$ \\
\hline 1 & 131 & 163.7 & 8 & 10 & 15 & 18.8 \\
\hline 2 & 155 & 193.8 & 10 & 12.5 & 12 & 15 \\
\hline 3 & 146 & 182.5 & 10 & 12.5 & 14 & 17.5 \\
\hline Arithmetic mean & 144 & 180 & 9.3 & 11.6 & 13.7 & 17.1 \\
\hline Minimal value & 131 & 163.7 & 8 & 10 & 12 & 15 \\
\hline
\end{tabular}

\section{Conclusion}

At welding $9-12 \% \mathrm{Cr}$ steels is very necessary to use not only pre-heating, but also subsequent tempering at relatively high temperatures. This ensures both decreasing of residual stresses and mainly carbon diffusion in martensite and thus also partial decreasing of material strength and hardness at simultaneous increasing values of ductility and impact toughness. Dynamic of the mentioned processes increases with increasing tempering temperature.

Nevertheless, it is not possible to use sufficiently high tempering temperatures at repairs. It is partly due to intensive oxidation on the machined parts surfaces, but mainly due to creation deformation, which can't be subsequently removed by following machining. Thus as a result, there is tendency to lower tempering temperatures as low as possible.

There is tempering of structure in the case of material GX12CrMoVNb9-1 as well as lowering of hardness values already at tempering temperature $550^{\circ} \mathrm{C}$ and holding time $30 \mathrm{Hrs}$. Entirely sufficient is then application of tempering temperature $580^{\circ} \mathrm{C}$ with holding time $30 \mathrm{Hrs}$. However, the same rules are not valid for the metal weld, despite the fact that electrodes BÖHLER FOX C 9 MV have the similar chemical composition as used parent material and are directly designed for welding P91/T91 (1.4903) steels. Lower tempering temperature can't decrease the hardness values in the weld metal fast enough - as it is in the case of parent material. Finally stated, boundary parameters of the subsequent heat treatment for weld metal are as following: tempering temperature $595^{\circ} \mathrm{C}$ and holding time minimal $30 \mathrm{Hrs}$.

In spite of fact that within all performed experiments there were measured hardness values below $350 \mathrm{HV}$ in the whole measured area, impact energy values in the weld metal are not sufficient. While value of impact energy KV2 is very high on the boundary between weld metal and HAZ (144 J), it didn't get over $15 \mathrm{~J}$ in the weld metal. 
Thus as a solution, there could be utilization of another type of filler metal that belongs into the same group 6.4. So as such material there can be used e.g. electrodes BÖHLER FOX 20 MVW that are designed for welding steels having higher $\mathrm{C}$ and $\mathrm{Cr}$ content (mainly X20CrMoV12-1, X20CrMoWV12-1, X22CrMoV12-1, X19CrMoVNb11-1 and GX22CrMoV12-1). These electrodes have much higher hardenability and immediately after welding are weld metal hardness values much higher than by electrodes BÖHLER FOX C 9 MV. However, there is simultaneous decrease of hardness below magnitude $350 \mathrm{HV}$ in the weld metal already at tempering temperature $550^{\circ} \mathrm{C}$ and holding time $46 \mathrm{Hrs}$ [14].

\section{Acknowledgement}

This publication was written at the Technical University of Liberec, Faculty of Mechanical Engineering with the support of the grant project MPO TRIO 10510 and with the support of the Institutional Endowment for the Long Term Conceptual Development of Research Institutes, as provided by the Ministry of Education, Youth and Sports of the Czech Republic in the year 2018.

\section{References}

[1] HANUS, P., SCHMÍDOVÁ, E. (2016) Influence of the Welding Process on the Martensitic and Dual Phase High Strength Steels, In: Manufacturing Technology, Vol. 16, 2016, pp. 702-707, ISSN 1213-2489.

[2] KUŚMIERCZAK, S., MAJZNER, T. (2016) Analysis of The Causes the Degradation of Part Steam Generator by Using Microscopy Methods. In: Manufacturing Technology, Vol. 16, pp. 995998, ISSN 1213-2489.

[3] NOVOTNÝ, J., HONZÍKOVÁ, J., PILOUS, V., STRÁNSKÝ, K.. (2015) Properties of Welded Joints in Power Plant. In: Manufacturing Technology, Vol. 15, pp. 1028-1032, ISSN 12132489.

[4] KUŚMIERCZAK, S. (2015) Evaluation of Degradation of Heat Stressed Pipelines. In: Manufacturing Technology, Vol. 15, pp. 10061010, ISSN 1213-2489.

[5] PATEK, M., SLADEK, A., MICIAN, M. (2015) Destructive testing of the weld joints on split sleeve for branch connections repairs. In: Communications - Scientific Letters of the University of Zilina, Vol. 17, Issue 4, pp. 65-69, ISSN 13354205.

[6] LEE, J. M., SEO, H.D., CHUNG, H. (2018) Efficient welding distortion analysis method for large welded structres In: Journal of Materials Processing Technology, Vol. 256, June 2018, pp. 36-50, ISSN 09240136.

[7] NOVOTNÝ, J., HONZÍKOVÁ, J., PILOUS, V., STRÁNSKÝ, K.. (2016) Verification for the Causes of the Degradation of Welded Joints in Power Plant. In: Manufacturing Technology, Vol. 16, pp. 1106-1110, ISSN 1213-2489.

[8] MIČIAN, M., PATEK, M., SLÁDEK, A. (2014) Concept of repairing branch pipes on highpressure pipelines by using split sleeve. In: Manufacturing Technology, Vol. 14(1), pp. 60-66, ISSN 1213-2489.

[9] LAYUS, P., KAH, P., KHLUSOVA, E., ORLOV, V. (2018) Study of the sensitivity of high-strength cold-resistant shipbuilding steels to thermal cycle of arc welding. In: International Journal of Mechanical and Materials Engineering, Vol. 13, Issue 1, 1 December 2018, ISSN 18230334.

[10] PURMENSKÝ, J., FOLDYNA, V., SONDEL, M., SCHWARZ, D., KOUKAL, J. Microstructure and creep rupture strength of welded joints in the steel P91. (2007) Proceedings of the ASME Pressure Vessels and Piping Conference - 8th International Conference on Creep and Fatigue at Elevated Temperatures, Pages 503-511, ISBN 0791842878;978-079184287-4.

[11] KOUKAL, J., SONDEL, M., SCHWARZ, D., FOLDYNA, V. (2011). Development and microstructure of advanced creep resistant ferritic steels. In.: International Journal of Microstructure and Materials Properties, Vol. 6, Issue 1-2, May 2011, pp. 122-131, ISSN 17418410.

[12] MOHYLA, P., HAVELKA, L., KOUŘIL, K. (2018) Mechanical properties testing of P92 welded joints prepared by manual metal arc welding. In: Tehnicki Vjesnik, Vol. 25, Issue 1, February 2018, pp. 60-63, ISSN 13303651.

[13] PANDEY, C., MAHAPATRA, M.M., KUMAR, P., SAINI, N., THAKRE, J.G., VIDYARTHY, R.S., NARANG, H.K. (2018) A brief study on $\delta$ ferrite evolution in dissimilar P91 and P92 steel weld joint and their effect on mechanical properties, In: Archives of Civil and Mechanical Engineering, Vol. 18, Issue 3, July 2018, pp. 713722, ISSN: 16449665.

[14] MORAVEC, J. (2017). Experimenty svařování materiálu GX23CrMoV12-1. TUL_Z_17_VS_GX23CrMoV12-1_01, TU v Liberci, Liberec, pp. 1-39. 